\title{
The Demand for Primary Health Care Service in Nigeria: New Evidence from Facility Determinants
}

\author{
Uche Abamba Osakede \\ Bowen University, Nigeria \\ Email: royaluchechukwu [AT] gmail.com
}

\begin{abstract}
Despite high distribution of Primary Health Care Centres (PHC) and low cost of care provision, patronage is low in Nigeria. Findings for the determinants of health care demand are one sided with focus on patient related factors. Less attention is given to facility determinants. This study examined facility determinants of the demand for PHC service in Nigeria using basic infrastructures, equipment and staff type. The 2013-2014 SDI data covering 11,690 primary health care facilities was used. The Negative Binomial regression model was fitted to determine the effects of facility factors on number of visits. The results show more community workers and paraprofessionals and few medical Doctors and Nurses in PHC's. Facilities are equipped with weighing scales, sphygmomanometer and stethoscope with few thermometer. High staff absence rate, lack of improved water source and non-regular power supply are also observed. Findings associate presence of Nurses with increased number of visits than other staff type. Child weighing scale, regular power supply and improved water are also key positive determinants. Better use of PHC's in Nigeria is possible with medical personnel especially nurses in employment. Improved water, regular power and instruments like child weighing scale are also vital.
\end{abstract}

Keywords--- Demand, Primary health care, Health Facility, SDI data, Negative Binomial Model, Poisson, Infrastructure, Nigeria

\section{INTRODUCTION}

Primary Health Care (PHC) service was formed in accordance with the Alma Ata Declaration of 1978 by the member nations of the World Health Organization (WHO). The establishment of Primary Health Care Centers (PHCs) is mainly to provide accessible, affordable and available PHC to individuals. In Nigeria, the best possible definition of the services provided at the PHC level has is defined by the National PHC Development Agency as "the basic minimum health care package". Service provided in this package includes maternal and child health care needs; immunization and family planning, prevention and control of locally endemic diseases, treatment of common ailments and injuries, provision of essential drugs, health education, nutrition, sanitation, safe water supply and general community health service ${ }^{1,2,3}$. Despite the health benefits of PHCs in terms of access and low cost, there are records of underutilization. In Nigeria for instance, PHCs provision accounts for only about $5-10 \%$ of its potential patient load ${ }^{3}$. This statistics prevails in spite of evidences that the country has more PHC centers than secondary and tertiary health care providers. For instance, the FMOH estimated a total of about 23,640 health facilities in Nigeria, of which $85.8 \%$ are primary, $14 \%$ secondary and $0.2 \%$ tertiary ${ }^{4}$.

Given the availability of PHCs, adequate use of service provision would clearly abate the prevailing poor health condition in the country ${ }^{5,6}$ However the low patronage raises concern as to why most persons do not seek health care from PHC centers. This study is an inquiry into factors that influence the demand for PHC services in Nigeria using facility level data. This is because studies have generally focused on determinates of health care demand in relation to patient related factors with very little attention to facility contributing factors $7,8,9,10,11,12$. Facility related factors is commonly neglected due to difficulty in obtaining facility level data and often times, the data set is not available. This study is able to overcome this difficulty with use of the Service Delivery Indicator (SDI) data set recently introduced by the World Bank in partnership with the African Economic Research Consortium (AERC), and the African Development Bank (ADB). This data set provides information for education and health facilities for selected countries in Africa. The study seeks to extend literature findings to outpatient demand for PHC services using facility level determinants.

The demand for health carries with it monetary and non-monetary costs. Money spent on health virtually excludes expenditure on other consumption goods and time spent to obtain good health will not be available for other activities. In developing economies like Nigeria where there is high poverty prevalence and poor health indices, the purchase of good health is somewhat secondary in the bid to make ends meet. This further worsens health conditions and inevitably promotes poverty prevalence.

Theoretical explanations of how health seeking behavior is influenced by several factors, are originally hinged on conventional demand theory. The demand for health care in this case is derived from reduced form equations of the 
individual's utility maximization framework. Using this framework, demand for health care can be measured using the number of visits to a particular health facility. In this light the demand for health care services is predicated on the price of health care goods and services, alternative services, household income and taste. The use of the conventional theory of health care demand had been criticized for the neglect of the role of quality in the demand for health care. The framework also ignored the impact of the opportunity cost of time on the demand for health ${ }^{13}$.

Another dimension of examining the demand for health relates to differences in choice of health care facility by individuals from poor and rich households. With the use of survey data conducted in Cairo, Egypt, it was showed that affluent consumers prefer private and charitable hospitals than public providers of health care. The choice of such health facility relates with the higher quality of care provided. Effective demand which characterize such group of persons enables purchase of quality health care regardless of the associated high cost of the service. Other control variables; age, sex, education, and insurance were observed as major determinants of the individual's demand for health care. However the quality variation across facility was not accounted for due to data limitations on quality of health care service delivery from the service provider ${ }^{7}$.

In Nigeria, it is shown significant increase in the demand for health care with improvements in quality. Suggestive of higher revenue generation for facilities with quality health care delivery ${ }^{8}$. Where quality variables such as delay in payment of salaries, absenteeism, availability of power, and staff capacity are controlled for the results would be closer to the existing Nigerian situation.

Evidence of patient related factors that influence health care demand includes variables such as age, sex, healthy days, educational attainment, household size and distance of health facility to location of health care provider ${ }^{9}$. Income level is also shown to be a key determinant especially for preventive care ${ }^{12}$.

Findings for PHC in rural areas in Bangladesh show that they are characterized by lack of adequate health professionals, misuse of resources, provider absenteeism and provider-centric consultations ${ }^{10}$. The overall effect was ineffective delivery and patient dissatisfaction reducing PHC demand.

In Nigeria where PHCs are relatively more than other health care types yet with existing low demand for its services examining factors that influence demand of it services particularly from the facility level is vital.

\section{METHODS}

The theoretical framework for this study borrows from the specification of ${ }^{14}$ with further adjustments in line with ${ }^{15}$ Assuming individuals derive satisfaction from the consumption of both health and non-health goods, the utility function of a typical consumer can be stated as;

$U=U(H, Z)$

Where $\mathrm{H}$ and $\mathrm{Z}$ represents the total consumption of health and non-health goods and services respectively.

We suppose that the total consumption of health goods and services is seen as an investment in health that is influenced by a vector of medical inputs $(\mathrm{M})$, time spent seeking good health $\left(T_{h}\right)$, the consumers stock of knowledge $\boldsymbol{E}_{\boldsymbol{C}}$ as well as the staff type of providers of health care in a given facility $\boldsymbol{S}_{\boldsymbol{t}}$. The investment in health is hence specified as;

$I=I\left(M, T_{h}, E_{C}, S_{t}\right)$

Where the total investment in health equals consumption, then the health variable in equation 1 can be specified as;

$$
H=H\left(M, T_{h}, E_{C}, S_{t}\right)
$$

The total amount of non-health goods and services consumed $Z$ is also assumed to depend on a vector of non-health inputs $\mathrm{X}$, Time input $T_{n h}$, and the consumers stock of knowledge $E_{C}$. Hence $\mathrm{Z}$ in equation 1, can be specified as;

$Z=Z\left(X, T_{n h}, E_{C}\right)$

Substituting for $\mathrm{H}$ and $\mathrm{Z}$ in equation 1 , the utility function of the consumer becomes

$U=U\left[H\left(M, T_{h}, E_{C}, \boldsymbol{S}_{t} \cdot\right), Z\left(X, T_{n h}, E_{C}\right)\right]$

The consumer maximizes equation 5 subject to the goods budget constraint 
$Y=P_{m} M+P_{x} X$

Where Y represents the consumer's income, $P_{m}$ is the price of medical input, $P_{x}$ the price of non-medical input and X nonmedical consumption. The optimization problem is hence stated as

$\pi=\boldsymbol{U}\left[H\left(M, T_{h}, E_{C}, \boldsymbol{S}_{\boldsymbol{t}}\right), Z\left(X, T_{n h}, E_{C}\right)\right]+\lambda\left(Y-P_{m} M-P_{x} X\right)$

The first-order conditions for the individual's decision problem are:

$$
\begin{aligned}
& \text { M: } U_{H} H_{M}=\lambda P_{M} \\
& T_{h}: U_{H} H_{T h}=\lambda Y \\
& X: U_{Z} Z_{X}=\lambda P_{X} \\
& T_{n h}: U_{z} Z_{T_{n h}}=\lambda Y \\
& \lambda: Y-P_{m} M-P_{x} X=0 \\
& \text { Equations } 7 \text { a to } 7 \mathrm{e} \text { can be solved } \\
& \text { time spent seeking good health, } \\
& \text { 7a M }{ }^{*}=D_{m}\left(Y, P_{M}, P_{X}, E_{C}, E_{h}\right) \\
& \text { 7b } T_{h}^{*}=D_{T h}\left(Y, P_{M}, P_{X}, E_{C}, E_{h}\right) \\
& \text { 7c } X^{*}=D_{x}\left(Y, P_{M}, P_{X}, E_{C}\right) \\
& \text { 7d } T_{n h}^{*}=D_{T_{L}}\left(Y, P_{M}, P_{X}, E_{C}\right)
\end{aligned}
$$

Equations 7a to 7e can be solved jointly to obtain the general form of the individual's demand function for medical input, time spent seeking good health, non-health goods and time spent seeking non-health goods.

Given the optimal demand for health as reflected in the demand for medical good $\left(\mathrm{M}^{*}\right)$ and time spent seeking good health $T_{h}$, it is apparent that the individuals demand for health can be influenced by the consumers income Y, price of medical goods $P_{M}$, price of non-medical goods $P_{X}$, educational attainment of the consumer $E_{C}$ and type of health care provider $\boldsymbol{S}_{\boldsymbol{t}}$. Hence the demand for health can be specified as

$D_{H}=D_{H}\left(Y, P_{M}, P_{X}, E_{C}, \boldsymbol{S}_{\boldsymbol{t}}\right)$

${ }^{16}$, highlights facility variables that influence the demand for health care such as the quality of health care service delivery $\left(Q_{s}\right)$, Demographic location of the health facility that is in the urban or rural area $(D)$ and institutional factors $(I)$ . Taking cognizance of these factors, equation 8 becomes;

$D_{H}=D_{H}\left(Y, P_{M}, P_{X}, E_{C}, \boldsymbol{S}_{\boldsymbol{t}}, Q_{s}, D, I\right)$

Variables such as consumers income, $\mathrm{Y}$, price of medical care $\mathrm{P}_{\mathrm{M}}$, price of non-health good $\mathrm{P}_{\mathrm{X}}$, and educational attainment of the consumer, are omitted in the empirical model for this study due to limitations with obtaining data. The SDI data set is yet to make publicly available results for patient interview which would give access to information regarding the users of the health facilities surveyed. The model estimated is hence

$D_{H}=D_{H}\left(\boldsymbol{S}_{t}, Q_{s}, L_{f}, I\right)$

If the demand for health care is measured as the number of outpatient visits, then health care demand in a PHC facility can be stated as;

Outpatient visits $=f($ Stafftype, Medequip, Staffabsc, Basicinf, Demoloc, Salarydelay $)$

Staff type is considered along four categories; medical doctor, nurse, community worker and paraprofessional. The quality of health care service delivery is examined in three different ways which are the availability of functioning medical equipment (thermometer, Sphygmomanometer, stethoscope, adult, child and infant weighting scale), Staff absence and the availability of functioning basic infrastructural facilities (water, electricity, and toilet facilities). We also included the demographic location of the facility whether in the urban or rural area. Institutional influence (I), is also considered using delay in salary. 
The inclusion of staff type is considered vital as it would reflect in the quality of service delivered and hence influence the satisfaction of users and visit to the facility. The role of each medical personnel differs and it would be interesting to know how each medical staff influences use of facility. Inclusion of medical equipment is considered as a facility level determinant of health care demand because individuals would ordinarily be encouraged to patronize services in a health facility equipped with functioning medical equipment. Absence of staff is also seen as an important determinant because where users of a particular health care facility do not meet with the individuals meant to provide required service, they would be discouraged from use of such facility. Infrastructures such as water, electricity and toilet facilities are also included as regressors because they are seen as basic amenities that should be in a health care facility and availability would undoubtedly encourage use of services. We also included the geographical location of the PHC as a regressor to determine whether use is based on locality of the facility in urban or rural areas. The role of institution in terms of salary delays is also considered an important predictor of PHC demand. This is because it is expected that salary delay would demotivate staff performance and in turn promote poor service delivery as well as less use of health facility.

The variables used to measure basic infrastructure are quite similar to that by ${ }^{16}$ and ${ }^{15}$ The approach by ${ }^{15}$ is appreciable especially for power and water variable. Here the variable for power is generated as an interaction of public electricity with use of a generator set to capture stable power supply. This is interesting for the Nigerian situation commonly characterized with erratic power supply. It is possible to have available but nonfunctioning medical equipment and infrastructural facility. Hence only available and functioning medical equipment and infrastructure were used in the model. This is done by interaction of response to the question whether the medical equipment and infrastructure is available and if it is functioning. For ease of access of good water source, water source is considered as an interaction of improved water source with less than 5 minutes' walk from water source to the health facility. To capture steady electricity supply in the health facility, availability of publicly provided electricity would be interacted with ownership of a generator set. This is mainly due to constant publicly provided electricity interruption in Nigeria ${ }^{17,18}$. Similarly, availability of improved toilet facility was interacted with those that are functioning.

The dependent variable used in the study is in counts of the number of outpatient visits and hence requires use of the poisson regression model. This is because the poisson model best suites dependent variables measured as count data ${ }^{19}$ The distribution of the poisson model is shown as

$$
P_{Y}=\frac{\beta^{Y} e^{-\beta}}{Y^{!}}
$$

Where $Y$ is the number of events occurring in a fixed period of time and $\beta$ is the intensity parameter showing the expected number of occurrence of $Y$. It is observed that an increase in $\beta$ naturally lends the poisson to a normal distribution. The poisson regression model is examined as a log likelihood function and hence provides maximum likelihood estimates for the slope and intercept coefficients. The model is also assumed to have an equal dispersion property for the mean and variance. Such that if $y$ is the number of events occurring in a fixed period of time, then the conditional expectation of the mean given $\mathrm{x}$ equals the conditional variance;

$$
E\left(\frac{Y}{X}\right)=\operatorname{Var}\left(\frac{Y}{X}\right)=\mu
$$

A violation of this assumption requires the use of variants of the poisson model such as the negative binomial regression model (NBRM) or the zero inflated poisson (ZIP). The ZIP is preferred where the outcome variable has excess zeros.

Data for this study was obtained from the 2013-2014 Nigeria Service Delivery Indicators, provided by the World Bank. SDI tracks performance and quality of service delivery in primary schools and frontline health facilities across Africa. ${ }^{20}$ The SDI Health Survey covered indicators such as: Health facility information, Infrastructure availability, Medical equipment availability, Drug availability, Health provider information among others ${ }^{20}$.

The survey design in Nigeria, focused on selected states and Local Government Areas (LGA's) in each state. The 20132014 SDI data was obtained from twelve states $^{1}$ of the federation. The health survey covered a total of 22,057 health care facilities. From the total health care providers surveyed, PHC facilities mainly dispensaries and health centers, made up approximately $53 \%(11,690)$, state hospitals; $40 \%(8,823)$ and other facility types $6 \%(1323)$. Data for the number of visits were collected over the number of consulting staff. Health care facilities were required to provide this information in the last three months preceding the survey.

${ }^{1}$ There are a total of thirty-six states in Nigeria. The survey covered 12 states with focus on more northern states than in other zones in the country. Northern states were six in number (Bauchi (8.95\%), Kaduna (11.42\%), Kebbi (6.66\%), Kogi $(9.13 \%)$, Niger $(6.46 \%)$, Taraba $(5.55 \%)$ ), Eastern states; two were covered (Anambra (4.60), Imo (8.43\%), Southern states; two covered (Bayelsa $(8.18 \%)$, Cross River $(7.68 \%)$,

Western States also included two (Osun (8.60\%), Ekiti (14.34\%) (World Bank, 2018) 


\section{RESULTS AND DISCUSSION}

The distribution of the data for outpatient visit is shown in figure 1. The nature of the data suggests dispersion in the data in terms of mean and variance. This is because of the skewness of the data to the left and high facility frequency distribution for the number of facilities that recorded over 200 outpatient visits in the last three months preceding the survey.

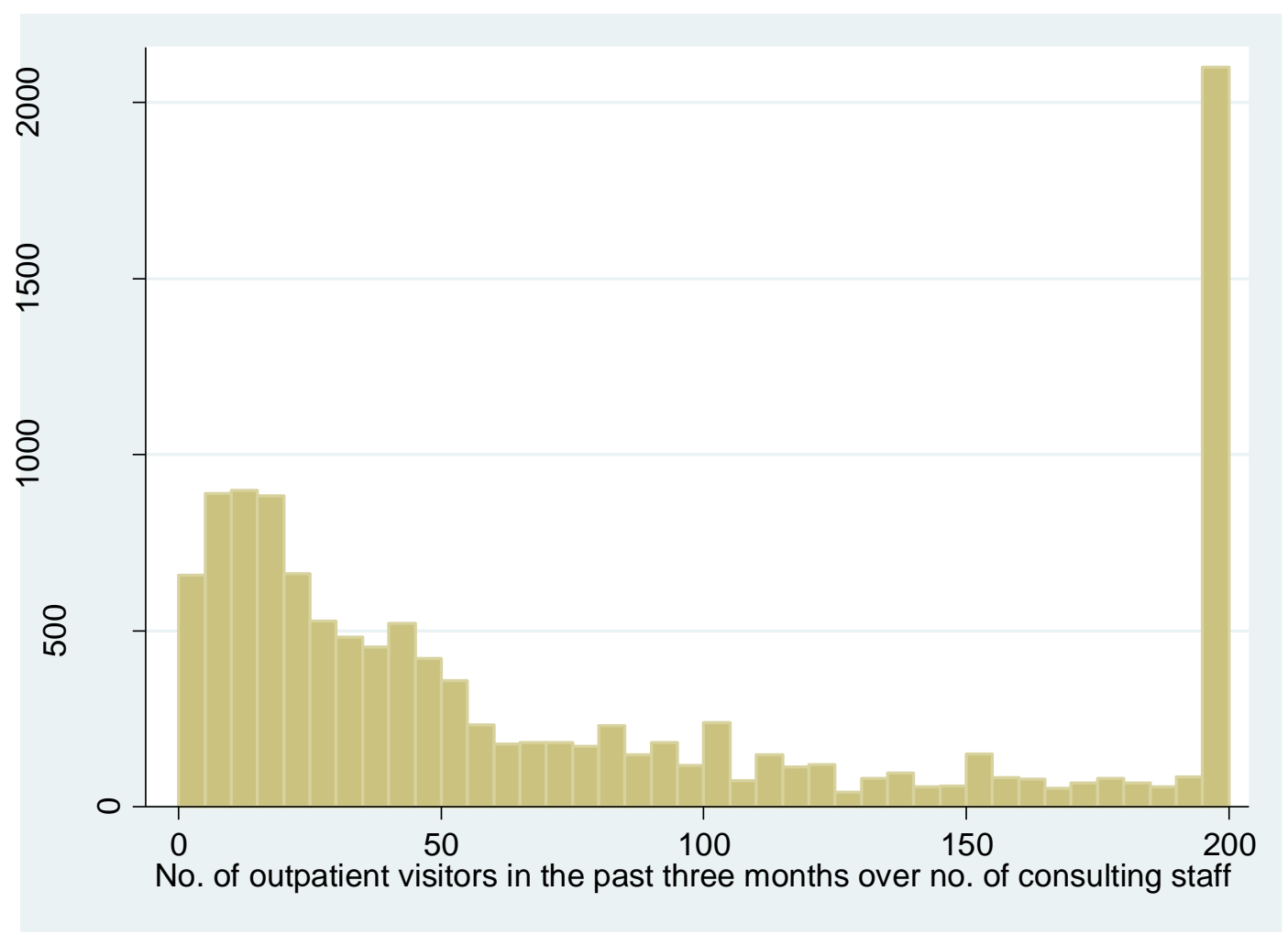

Figure 1: Graphical representation of outpatient visits

The statistics in figure 1 shows that approximately 600 facilities did not have any outpatient visits over a span of three months ratifying existing low use of PHCs in Nigeria. The data also shows that about 800 PHCs had records of between 5 to 15 outpatient visits over the same period. As outpatient visits increased from between 25 to 190, the number of facilities that had such visits dropped from about 800 to approximately 80 in number. This distribution is depicted by the left skewness of the data. The data hence depicts that aside the high number of facility response to having 200 outpatient visits, the number of facilities that responded to outpatient visits dropped with increase in the number of outpatient visits. The skewness of the distribution, suggests that that majority of the health care facilities surveyed had very low number of outpatient visits except for those facilities that reported over 200 outpatient visits. This is worrisome given large distribution of PHCs in Nigeria compared to other health care provider type.

Estimates of the mean and variance of the dependent variable along with descriptive statistics of the variables used in the study are shown in table 1 . The statistics for outpatient visits validates dispersion of the data for outpatient visits. The result shows unequal mean and variance of the distribution for outpatient visit. The figures show mean value of about 76.968 and variance of 5046.831. This finding suggests the use of variants of the poisson model particularly the negative binomial model as there are no excess zeros in the data for outpatient visit.

Table 1: Descriptive Statistics

\begin{tabular}{|l|r|r|}
\hline Variable & Observation & Mean (\%) \\
\hline Outpatient visits & 12235 & 76.96763 \\
\hline Outpatient visits (Variance = 5046.831) & & \\
\hline Medical doctor & 12478 & 0.035663 \\
\hline
\end{tabular}




\begin{tabular}{|l|r|r|}
\hline Nurse & 12478 & 0.27272 \\
\hline Community worker & 12478 & 0.595448 \\
\hline Paraprofessional & 12478 & 0.096169 \\
\hline Thermometer & 12478 & 0.096169 \\
\hline Sphygmomanometer & 10694 & 0.934075 \\
\hline Stethoscope & 10848 & 0.868824 \\
\hline Adult weighing scale & 11060 & 0.902441 \\
\hline Child weighing scale & 7162 & 0.872522 \\
\hline Infant weighing scale & 8559 & 0.897652 \\
\hline Absence & 12551 & 0.537089 \\
\hline Water & 12212 & 0.424091 \\
\hline Power & 12428 & 0.339154 \\
\hline Toilet facility & 5393 & 0.49249 \\
\hline Urban location & 12551 & 0.495578 \\
\hline Salary delay & 12551 & 0.194088 \\
\hline
\end{tabular}

Source: Authors computation from SDI Data

The descriptive statistics of the variables used in the model reveals that PHCs in Nigeria are characterized mainly with community workers than any other medical employment type. From about 12,478 PHC facility responses to medical employment type, approximately $60 \%$ had community workers in employment, $10 \%$ had paraprofessionals and $28 \%$ indicated that they nurses in employment. Facilities with medical doctors were very few standing at approximately $4 \%$. The large number of community workers in employment across PHCs suggests low quality medical delivery. Community workers have basic medical training and are not be able to manage medical conditions that require higher medical training. Such distribution of medical workers can negatively affect the demand for PHC service.

In terms of medical equipment, not many facilities had thermometer. Only about $10 \%$ of the facilities had thermometers. The PHCs were equipped with Sphygmomanometer (93\%) and Stethoscopes (87\%). The distribution of weighing scale for infant, child and adult is in close range; between $87 \%$ and $90 \%$.

Staff absence was observed as significantly high showing approximately $54 \%$ absence rate. Most of the staff employed in PHCs were not at the Centers at the time of the survey.

In terms of basic infrastructural distribution, less than half of the facilities (43\%) had improved water source. Only $34 \%$ of the facilities had steady power and approximately50\% had improved toilet facilities for outpatient use. This suggests a major challenge with stable power for most PHCs. Where there are no electricity supply, the PHCs will be in total blackout. This is worrisome particularly for refrigeration of vaccines for children and other medical procedures requiring use of electricity. Improved water source and toilet facility also appears to be scarce in most facilities. Shortage of such facility further endangers health conditions of users and employees of the facility.

PHCs are fairly distributed across rural and urban location with approximately 50\% across each location. Rural and urban dwellers hence have equal access to PHCs in terms of distribution of the facilities. Salary delay is not a common experience as only about $19 \%$ of the facilities indicated cases of delay in salary.

Using the NBRM to examine how facility level determinants affect use of PHC service, it is observed that having medical doctors, nurses and also community workers is crucial for increased demand of PHC services. The NBRM result for facility level determinants of PHC is shown in table 2 
Table 2: NBRM result on facility level determinants of the demand for PHC

\begin{tabular}{|c|c|}
\hline \multicolumn{2}{|c|}{ Dependent variable: No of outpatient visits } \\
\hline \multicolumn{2}{|c|}{ Staff type: Reference category is Paraprofessional } \\
\hline Medical doctor & $\begin{array}{l}0.569 * * * \\
(0.096)\end{array}$ \\
\hline Nurse & $\begin{array}{l}0.708 * * * \\
(0.072)\end{array}$ \\
\hline Community worker & $\begin{array}{l}0.585 * * * \\
(0.067)\end{array}$ \\
\hline \multicolumn{2}{|l|}{ Medical Equipment } \\
\hline Thermometer & $\begin{array}{l}-0.12 \\
(0.082)\end{array}$ \\
\hline Sphygmomanometer & $\begin{array}{l}0.074 \\
(0.085)\end{array}$ \\
\hline Stethoscope & $\begin{array}{l}0.052 \\
(0.14)\end{array}$ \\
\hline \multicolumn{2}{|l|}{ Weighing scale } \\
\hline Adult weighing scale & $\begin{array}{l}-0.008 \\
(0.082)\end{array}$ \\
\hline Child weighing scale & $\begin{array}{l}0.625^{* * * *} \\
(0.091)\end{array}$ \\
\hline Infant weighing scale & $\begin{array}{l}0.19 * * \\
(0.094)\end{array}$ \\
\hline Absence & $\begin{array}{l}0.008 \\
(0.037)\end{array}$ \\
\hline Water & $\begin{array}{l}0.069 * \\
(0.041)\end{array}$ \\
\hline Power & $\begin{array}{l}0.345^{* * * *} \\
(0.04)\end{array}$ \\
\hline Toilet facility & $\begin{array}{l}-0.044 \\
(0.04)\end{array}$ \\
\hline \multicolumn{2}{|c|}{ Location of facility: Reference category Rural } \\
\hline Urban location & $\begin{array}{l}-0.057 \\
(0.044)\end{array}$ \\
\hline Salary delay & $\begin{array}{l}0.213 * * * \\
(0.052)\end{array}$ \\
\hline _cons & $\begin{array}{l}3.000 * * * \\
(0.18)\end{array}$ \\
\hline $\begin{array}{l}\text { lnalpha } \\
\text { _cons }\end{array}$ & $\begin{array}{l}-0.175^{* * * *} \\
(-6.78)\end{array}$ \\
\hline $\begin{array}{l}\text { Number of observation } \\
\text { Test of overall model fit: LR chi } 2569 \\
\text { Prob }>\text { chi } 2=0\end{array}$ & 202.68 \\
\hline
\end{tabular}

Note: NBRM coefficients reported with standard error in brackets $* * * \mathrm{p}<0.01, * * \mathrm{p}<0.05, * \mathrm{p}<0.1$

The result suggests that employing more Nurses will cause higher demand for use of PHC care relative to other staff type. With Paraprofessional as the reference group for staff type, the result suggests that the expected log count for the demand of PHCs with Nurses is about 0.71 higher with than the expected log count of employing paraprofessionals.

Similarly, the expected log count for community worker and Medical doctor is approximately 0.59 and 0.57 higher than the expected log count for paraprofessionals. The implication therefore is that for achieving better use of PHC service, the employment of nurses should take utmost priority in terms of staff strength. Medical doctors should also be employed in 
same proportion with community workers. Existing statistics as shown in table 1 indicates more community workers than other staff type. A reshuffle of staff arraignment would promote better use of the facility.

The test of overall model significance as shown by the probability value of the Wald chi2 test indicates that the coefficients are not equal to zero.

The result for medical equipment did not show any significant effect on the demand for PHC service. Facilities with weighing scales particularly child and infant weighing scales, have more tendency to attract utilization of service. The result for child weighing scale indicates that the expected log count of use of PHC service with child weighing scales is about 0.63 higher than without having no child weighing scale. Similarly, the expected log count of utilization when facilities are equipped with infant weighing scale is 0.19 higher than without it.

The result also showed that having water and power is crucial for use of PHC service. The expected log count of PHC demand is about 0.07 higher when facilities are equipped with improved water with less than five minutes' walk. In the same way, the expected log count of use of PHCs when equipped with regular power supply is about 0.35 higher than with irregular power. The relatively higher log count for power suggests extremely significant role of power for use of PHCs. In the Nigerian case, erratic power supply is a common phenomenon and where this situation is addressed, use of PHC service will unequivocally improve.

Findings further suggests that the use of PHC service is not dependent on demographic location of the facility. Hence, the existing low demand for PHC service is prevalent not only in the rural but also urban areas. The result for salary delay on PHC demand is different from apriori expectation. Ordinarily, it is expected that salary delay would demotivate staff and promote poor service, provision and hence reduce use of PHC. On the contrary, facilities that experience salary delay also recorded significant increase in the use of health care service. The log count of PHC demand in facilities with salary delay is about 0.21 higher than facilities that do not experience delay in salary. It is possible that staff motivation results from receiving tokens from patients while waiting for salary payment. The additional income received from patients may encourage better service provision as staff also anticipate salary payment from the government. Extra care and concern can then be meted to patients encouraging use of the facility.।

\section{CONCLUSION}

This study examined the factors that influence the demand for PHC service in Nigeria using data from the SDI survey. The analysis was conducted using the NBRM. Findings from data distribution for variables showed that PHCs in Nigeria employ mainly community workers as medical staff with very few having medical doctors and nurses in employment. They are well equipped with weighing scale both for children and adults. They ae also reasonably equipped with medical equipment such as thermometer sphygmomanometer and stethoscope. Absence rate for staff is considerably high and most facilities do not have improved water and power.

The result from the NBRM suggests that the low patronage of PHCs in Nigeria is very much associated with the quality of service delivery. Having available and functioning medical equipment such as weighing scale as well as basic infrastructural facilities like water and power significantly increases the demand for PHC service. In terms of staff type, PHC demand would reasonably rise when they employ medical personnel such as nurses, community workers and medical doctors than paraprofessionals. The results also suggests that the low demand for PHC in Nigeria is a general phenomenon both in the rural and urban areas.

Findings of the study suggests that utilization rates for PHC service in Nigeria would rise if policy actions ensure that facilities are well equipped with more nurses than community workers than any other staff type, basic infrastructural facilities such as water and power and medical equipment like weighing scale particular for children. Such provision should cut evenly across urban and rural areas to ensure overall rise in the demand for PHC.

\section{REFERENCES}

1. Federal Ministry of Health (FMOH) (2006) Revised policy-program and strategic plan of action Department of Health Planning and Research, National Health Management Information System (NHMIS) Unit, Abuja . 2. World Health Organization WHO (2008) The World Health Report. Primary care-now more than ever. retrieved from http://www.who.int/whr/2008/en/ $\quad$ accessed $\quad$ sept $\quad 29, \quad 2016$ 3. Federal Ministry of Health (FMOH) (2004) Revised national health policy Abuja. 4. Federal Ministry of Health (FMOH) (2005) Inventory of health facilities in Nigeria, Abuja. 5. World Health Organization (WHO) (2014) Trends in maternal mortality 1990-2013. Retrieved June 6th, 2014, from www.who.int/gho/countries/nga/country-profiles/en. 
6. United Nations International Children's Emergency Fund (UNICEF) (2014) Nigeria at a glance. Retrieved May 3rd, 2014, from www.unicef.org/infobycountry/nigeria_statistics.html.

7. Ellis R.P.1. McInnes D.K \& Stephenson E.H. (1994) Inpatient and outpatient health care demand in Cairo, Egypt. Health Econ. 3(3):183-200

8. Akin J.S.1, Guilkey, D.K \& Denton, E.H. (1995) Quality of services and demand for health care in Nigeria: a multinomial

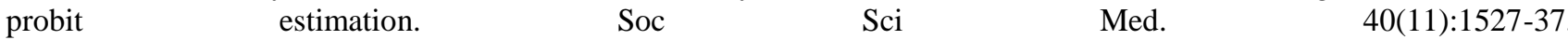
9. Sarma, S. (2009) Demand for outpatient healthcare: empirical findings from rural India Appl Health Econ Health Policy; 7(4):265-77

10. Kamrul M.D. H (2012) Quality of primary health care services in rural Bangladesh: patients' perspectives. Issn $1923-$ 6662

(online)

11. Purohit, B. C. (2013) Demand for healthcare in India. Health care in low resource settings ; Vol 1 , No 1

12. Arendt J.N. (2012) The demand for health care by the poor under universal health care coverage Journal of Human Capital.; volume 6, Number

13. Becker G.S. (1965) A theory of time allocation. The Economic Journal; Vol 75, No 229, pp 493-519.

14. Abamba U. (2016) Malaria in Nigeria: Implications for Labour market and cost outcome. Unpublished Phd Dissertation. University of Ibadan, Nigeria.

15. Ayadi, M. O, Osakede, A.U and Lawanson A. O (2016) The Effects of health care service delivery on health outcomes: Evidence from Service Delivery Indicators Survey. Paper presented at the African Economic Research Consortium National Policy Workshop on Service Delivery Indicators (SDI): Evidence, Policy Outcomes and Actions, Abuja, October 13-14.

16. Bold T, Svensson J, Gauthier B, Mæstad O, \& Wane W. (2011) Service Delivery Indicators: Pilot in Education and Health Care in Africar $\quad$ REPORT 17. Arobieke O, Osafehinti S. \& Oluwajobi F. O.(2012) Electrical Power outage in Nigeria: History, causes and possible solutions. Journal of Energy Technologies and Policy; Vol 2 , No 6 . 18. Ohajianya A. C. Abumere, O. E. Owate, I. O. \&, Osarolube E. (2014) Erratic power supply in Nigeria: causes and solutions. International Journal of Engineering Science Invention;Volume 3 Issue $7 \quad$ PP.51-55 19. Poisson, S.-D. (2013) Researches into the Probabilities of Judgements in Criminal and Civil Cases Recherches sur la probabilité des jugements en matière criminelle et en matière civile Paris, 1837 Translated by Oscar Sheynin Berlin, ISBN 978-3-94294

20. World Bank (2018). Nigeria - Service Delivery Indicators Health Survey 2013-2014 - Harmonized Public Use Data 2018. Available at http://microdata.worldbank.org/index.php/catalog/2559/study-description 